\title{
Clinical significance of $\mathrm{CHD1L}$ in hepatocellular carcinoma and therapeutic potentials of virus-mediated $\mathrm{CHD} 1 \mathrm{~L}$ depletion
}

\author{
Leilei Chen, ${ }^{1,3,4}$ Yun-Fei Yuan, ${ }^{2}$ Yan Li, ${ }^{1}$ Tim Hon Man Chan, ${ }^{3,4}$ Bo-Jian Zheng, ${ }^{5}$ \\ Jun Huang, ${ }^{2}$ Xin-Yuan Guan ${ }^{1,3,4}$
}

\begin{abstract}
- Additional tables are published online only. To view these files please visit the journal online (http://gut.bmj. com)

${ }^{1}$ State Key Laboratory of Oncology in Southern China, Sun Yat-sen University Cancer Center, Guangzhou, China ${ }^{2}$ Department of Hepatobiliary Oncology, Sun Yat-sen University Cancer Center, Guangzhou, China ${ }^{3}$ Department of Clinical Oncology, The University of Hong Kong, Hong Kong, China ${ }^{4}$ State Key Laboratory for Liver Research, The University of Hong Kong, Hong Kong, China ${ }^{5}$ Department of Microbiology, The University of Hong Kong, Pokfulam, Hong Kong, China
\end{abstract}

\section{Correspondence to}

Professor Xin-Yuan Guan, State Key Laboratory of Oncology in Southern China, Sun Yat-Sen University Cancer Center, Guangzhou, China; xyguan@hkucc.hku.hk

$L C$ and $Y-F Y$ contributed equally to this paper.

Revised 8 September 2010 Accepted 29 September 2010 Published Online First 10 November 2010

\section{ABSTRACT}

Background Hepatocellular carcinoma (HCC) is among the most lethal of human malignancies. It is difficult to detect early, has a high recurrence rate and is refractory to chemotherapies. Amplification of $1 \mathrm{q} 21$ is one of the most frequent genetic alterations in HCC. CHD1L is a newly identified oncogene responsible for 1q21 amplification. This study aims to investigate the role of CHD1L in predicting prognosis and chemotherapy response of patients with $\mathrm{HCC}$, its chemoresistant mechanism and whether virus-mediated CHD1L silencing has therapeutic potentials for HCC treatment.

Methods The clinical significance of CHD1L in a cohort of 109 HCC cases including 50 cases who received transarterial chemoembolisation treatment was assessed by clinical correlation and Kaplan-Meier analyses. A CHD1L-overexpressing cell model was generated and the mechanism of chemoresistance involving CHD1L was investigated. An adenovirusmediated silencing method was used to knockdown $C H D 1 L$, and its effects on tumorigenicity and chemoresistance were investigated in vivo and in vitro. Results Overexpression of CHD1L was significantly associated with tumour microsatellite formation $(p=0.045)$, advanced tumour stage $(p=0.018)$, overall survival time $(p=0.002)$, overall survival time of patients who received transarterial chemoembolisation treatment $(p=0.028)$ and chemoresistance $(p=0.020)$ in HCC. Interestingly, CHD1L could inhibit apoptosis induced by 5-fluorourail (5-FU) but not doxorubicin. The mechanistic study revealed that the involvement of the Nur77mediated pathway in chemotherapeutic agent-induced apoptosis can dictate if $\mathrm{CHD} 1 \mathrm{~L}$ could confer resistance to chemotherapy. Furthermore, an adenoviral vector containing short hairpin RNAs against CHD1L (CHD1L-shRNAs) could suppress cell growth, clonogenicity and chemoresistance to 5-FU. An in vivo study found that CHD1L-shRNAs could inhibit xenograft tumour growth and increase the sensitivity of tumour cells to 5-FU in nude mice.

Conclusions This study highlighted for the first time the prognostic value of $\mathrm{CHD} 1 \mathrm{~L}$ in $\mathrm{HCC}$ and the potential application of virus-mediated CHD1L silencing in $\mathrm{HCC}$ treatment.

\section{INTRODUCTION}

Hepatocellular carcinoma (HCC) is one of the most common causes of cancer morbidity and mortality in Southeast Asia, China and the USA, where its incidence has increased by $>90 \%$ over the past three decades. ${ }^{12}$ Curative surgery offers the hope

\section{Significance of this study}

What is already known about this subject?

- Amplification of $1 \mathrm{q} 21$ is detected in $58-78 \%$ of human HCCs, and a target oncogene CHD1L responsible for this amplification event has been identified.

- CHD1L inhibits cell apoptosis by blocking the Nur77-mediated apoptotic pathway.

- The clinical significance of CHD1L and the therapeutic potentials of $\mathrm{CHD} 1 \mathrm{~L}$ are still unknown.

\section{What are the new findings?}

- CHD1L overexpression in HCC correlates with the unfavourable clinical features, chemotherapy responsiveness and survival of patients with HCC.

- CHD1L inhibits chemotherapeutic agent-induced apoptosis via the Nur77/cytochrome c/caspase 9 pathway, providing a novel insight into the underlying mechanism of chemoresistance in HCC.

- The involvement of the Nur77-mediated pathway in drug-induced apoptosis can dictate if CHD1L could confer resistance to chemotherapy.

- Virus-mediated CHD1L depletion can abolish the malignant phenotypes of tumour cells and increase chemosensitivity to chemotherapeutic agent.

How might it impact on clinical practice in the foreseeable future?

- CHD1L expression can be used to predict prognosis and chemotherapeutic response of patients with HCC.

- Virus-mediated CHD1L silencing might serve as promising novel therapeutic options for patients with HCC.

for long-term survival to patients suffering from HCC; however, patients are commonly diagnosed at the advanced stage and this means that liver resection is only suitable for a minority of patients. For the majority of patients, the median survival is $\sim 6$ months. ${ }^{3}$ Chemotherapy is one of the mainstay treatments for patients with inoperable disease. HCC is a chemoresistant cancer, and the efficacy of chemotherapeutic drugs is generally believed to 
depend on their ability to trigger apoptosis. ${ }^{4}$ Actually, HCC is one of the well identified cancers that are most resistant to systemic chemotherapy, with the reported response rate varying from $0 \%$ to $20 \%$ and a median survival of only 4 months. ${ }^{6}$ The overall poor outcome thus underlines the urgent need for reliable biomarkers in the diagnosis and prognosis of HCC and improved molecular targets for the development of more efficient treatments.

It is believed that HCC, like many other solid tumours, develops from the accumulation of alterations of cancer-related genes critical to processes such as cell proliferation, apoptosis and other functions. Amplification of chromosome $1 \mathrm{q}$ is the most frequent genetic alteration in HCC, which was detected in $58-78 \%$ of primary HCC cases by comparative genomic hybridisation. $^{7-9}$ The minimal amplified region has been narrowed down to $1 \mathrm{q} 21$, and a novel oncogene, CHD1L (also named $A L C 1$ ), has been identified. ${ }^{10}$ The oncogenic function of CHD1L in HCC development and progression has been demonstrated by both in vitro and in vivo studies. ${ }^{10-13}$ In the present study, the association between the CHD1L overexpression and clinicopathological features in HCC was investigated. As described previously, CHD1L is able to bind to Nur77 and inhibits the latter's nuclear to mitochondrial translocation, and the subsequent Nur77-mediated caspase activation and apoptosis, thereby strongly extending HCC cell survival by inhibiting Nur77-mediated apoptosis. ${ }^{12}$ In light of this, the effect of CHD1L on chemotherapy and the mechanism underlying the chemoresistance of HCC were also investigated. More interestingly, the viral delivery of small interfering RNA (siRNA) targeting CHD1L as cancer therapeutics was further investigated and is discussed in this study.

\section{MATERIALS AND METHODS}

\section{Patients and clinical specimens}

Between June 2001 and June 2008, a retrospective cohort of 109 patients with HCC who underwent hepatectomy at Sun YatSen University Cancer Center (Guangzhou, China) were enrolled into this study. All patients were diagnosed with primary HCC, and none had received prior radio- or chemotherapy before surgery. Of the 109 patients, 59 have developed recurrent HCCs within 4 years. Fifty patients had prechemotherapy biopsies and then received about three cycles of transarterial chemoembolisation (TACE) treatment (figure 1). The studies using human tissue were reviewed and approved by the Committees for Ethical Review of Research involving Human Subjects at University of Hong Kong and Cancer Center of Sun Yat-Sen University, China.

\section{TACE treatment}

Cisplatin (CDDP), 5-fluorourail (5-FU) and an emulsion consisting of doxorubicin (DOX) and lipiodol were injected in turn into the arteries that fed the tumours. The median dose of lipiodol was $10 \mathrm{mg}(5-20 \mathrm{mg})$. The doses of the chemotherapy agents were: DOX $60 \mathrm{mg} / \mathrm{m}^{2}$, CDDP $120 \mathrm{mg} / \mathrm{m}^{2}$ and 5-FU $600 \mathrm{mg} / \mathrm{m}^{2}$ every month for up to three cycles.

\section{Definition of an objective response}

The effects of TACE on the tumour were assessed by dynamic CT within the first month after TACE treatment. The tumour response was evaluated using the Response Evaluation Criteria in Solid Tumors criteria. ${ }^{14}$ Patients were categorised into two groups. Those whom did not obtain clinical benefit and developed progressive disease were classified as the 'chemotherapy-resistant'

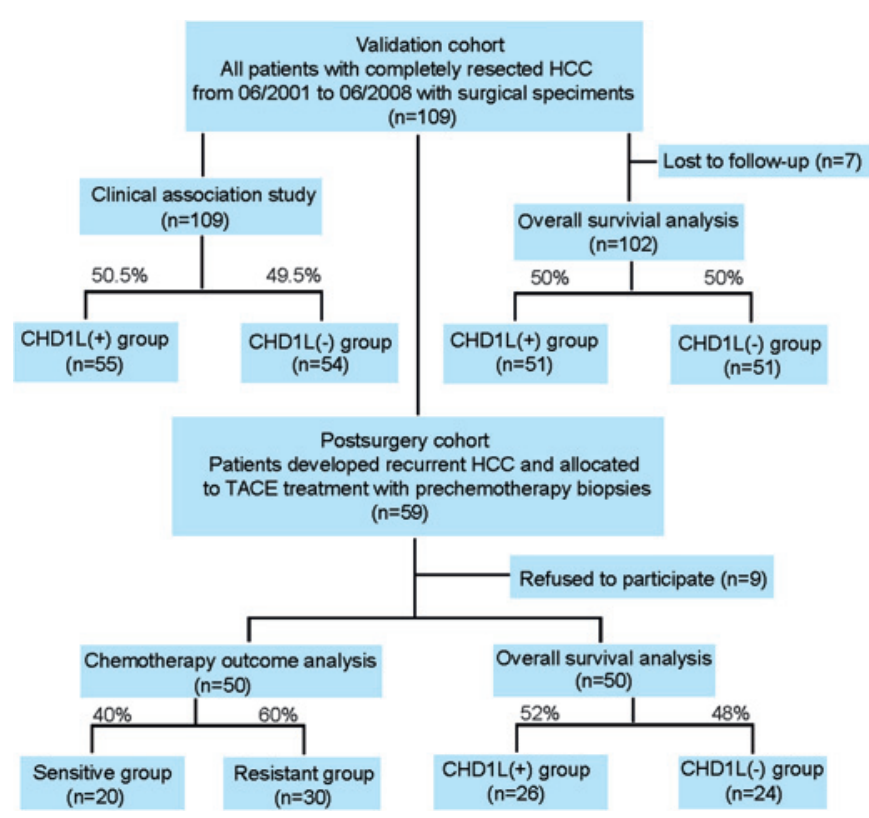

Figure 1 Study flow chart: inclusion criteria, exclusion criteria and outcome. HCC, hepatocellular carcinoma.

group. Those who obtained clinical benefit by achieving complete response, partial response and stable disease were classified as the 'chemotherapy-sensitive' group.

\section{Immunohistochemistry (IHC)}

IHC was performed as described previously. ${ }^{13}$ CHD1L immunoreactivity was scored as absent expression (0), weak expression (1), moderate expression (2) and strong expression (3) according to the semi-quantitative scoring method as reported by $\mathrm{Ng}$ et al. ${ }^{15}$ In this study, compared with non-tumour tissue, the higher IHC score of CHD1L in the tumour was defined as 'overexpression of CHD1L in HCC'. For prechemotherapy biopsies, a low (0-1) or high (2-3) IHC score of CHD1L in tumour tissue was defined as 'CHD1L-negative' or 'CHD1Lpositive' HCC, respectively. In this study, all histological evaluations were carried out in a double-blind manner by two pathologists to minimise observational bias.

\section{Cell lines}

HCC cell lines QGY-7703 and PLC8024 were obtained from the Institute of Virology, Chinese Academy of Medical Sciences, Beijing, China. The cells were maintained in Dulbecco's modified Eagle's medium (DMEM; Gibco BRL, Grand Island, New York, USA) supplemented with 10\% fetal bovine serum (FBS) (Gibco BRL). The cells were incubated at $37^{\circ} \mathrm{C}$ in a humidified chamber containing $5 \% \mathrm{CO}_{2}$.

\section{XTT proliferation assay}

Chemotherapy-induced cytotoxicity was determined by XTT Cell Proliferation Assay (Roche Diagnostics, Indianapolis, Indiana, USA) according to the manufacturer's instructions. The relative number of viable cells as compared with the number of cells without drug treatment was expressed as percentage cell viability using the following formula: cell viability (\%)= $\mathrm{A}_{490}$ of treated cells $/ \mathrm{A}_{490}$ of untreated cells. Three independent experiments were performed in duplicate.

\section{Confocal microscopy}

For visualising Nur77 protein, cells were transiently transfected with a green fluorescent protein (GFP)/Nur77 expression 
construct as described previously. ${ }^{12}$ For mitochondrial staining, before the fixation, Mitotracker Red (Molecular Probes, Eugene, Oregon, USA; $100 \mathrm{nM}$ ) was added to the culture medium and stained cells at $37^{\circ} \mathrm{C}$ for $15 \mathrm{~min}$. Slides were fixed and mounted with Vectashield Mounting Medium containing 4',6-diamidino-2-phenylindole (DAPI; Vector Laboratories, Burlingame, California, USA), and images were captured using a Zeiss LSM 510 Meta confocal laser-scanning microscope (Carl Zeiss MicroImaging, Thornwood, New York, USA).

\section{TUNEL assay}

Apoptotic cells were determined by the terminal deoxyribonucleotidyl transferase (TDT)-mediated dUTP-digoxigenin nick end labelling (TUNEL) assay. Apoptotic cells were determined using the In Situ Cell Death Detection Kit POD (Roche Diagnostics), which quantitatively determines DNA fragmentation visualised with a fluorescence microscope. Apoptotic indices were obtained by counting the percentage of TUNELpositive cells (green colour).

\section{In vitro tumorigenic assays}

For foci formation assay, $1 \times 10^{3}$ cells were seeded in a 6 -well plate. After culture for 7 days, surviving colonies ( $>50$ cells/ colony) were stained by Giemsa (Invitrogen, Carlsbad, California, USA) and counted. Anchorage-independent growth was assessed by colony formation ability in soft agar. Briefly, $1 \times 10^{4}$ cells were suspended in $1 \mathrm{ml}$ of soft agar mixture ( $2 \times \mathrm{DMEM}, 20 \% \mathrm{FBS}$ and $0.7 \%$ agarose) and were subsequently overlaid on the agar base. After $2-3$ weeks, colonies ( $\geq 10$ cells) were counted under the microscope in 10 fields per well. Three independent experiments were performed in duplicate.

\section{Antibodies and western blotting}

Mouse anti-CHD1L and $\beta$-actin antibodies were purchased from Abcam (Cambridge, MA, USA). Rabbit anticaspase 3, anticaspase 9 and anti-PARP (poly(ADP-ribose) polymerase) and mouse anticaspase 8 were all purchased from Cell Signaling Technology (Danvers, Massachusetts, USA). Mouse anticytochrome c (Cyto c) antibody was purchased from Santa Cruz
Figure 2 Overexpression of CHD1L was associated with a poor survival rate in hepatocellular carcinoma (HCC). (A) Representative images of CHD1L expression in a pair of HCC (right) and adjacent non-tumour liver tissue (left) detected by immunohistochemistry (IHC). Nuclear staining of CHD1L (brown) was detected in tumour tissue. The tissue sections were also stained with $\mathrm{H} \& \mathrm{E}$ as a reference. Original magnification, $\times 200$. (B) Representative images of H\&E staining (upper left) and IHC staining with an anti-CHD1L antibody (lower left) on serial sections of cirrhotic (Cir) tissue surrounding a HCC (Tu). The boxed regions are magnified and shown in the right panels. (C) H\&E staining (left) and IHC analysis of CHD1L (middle) were performed on serial sections of cirrhotic (Cir) tissue surrounding a HCC (Tu). The boxed regions are magnified and shown in the right panel. CHD1L was expressed in the cytoplasm of hepatocytes in cirrhotic tissue. (D) Kaplan-Meier overall survival (OS) curve of patients with HCC in correlation with CHD1L expression. The OS rate was significantly decreased in patients with HCC with CHD1L overexpression $(+)$ compared with patients without CHD1L overexpression $(-)(p=0.001)$. (E) Kaplan-Meier analysis indicated that the OS rate of patients with HCC who received transarterial chemoembolisation (TACE) was significantly decreased in the CHD1L $(+)$ group compared with the CHD1L(-) group $(p=0.028)$.
A
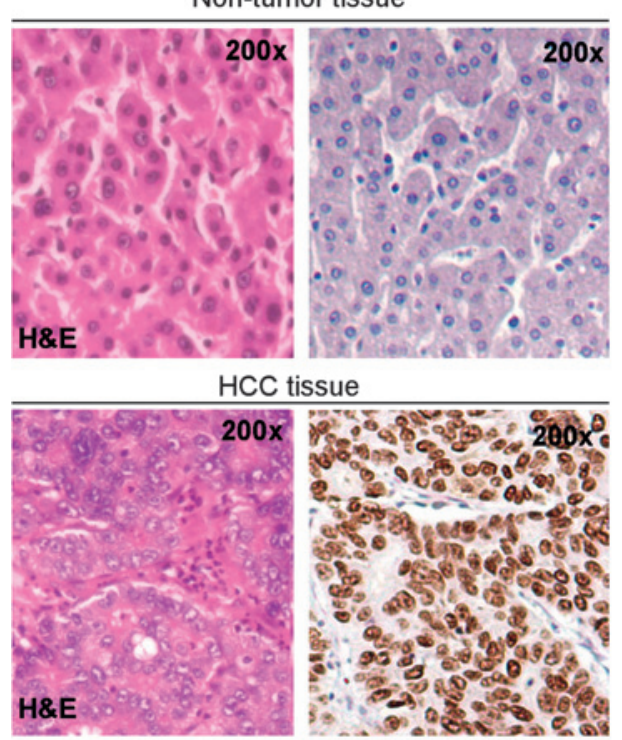

C

$H \& E$
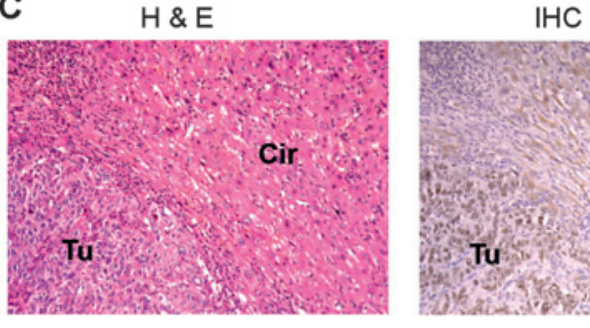

D

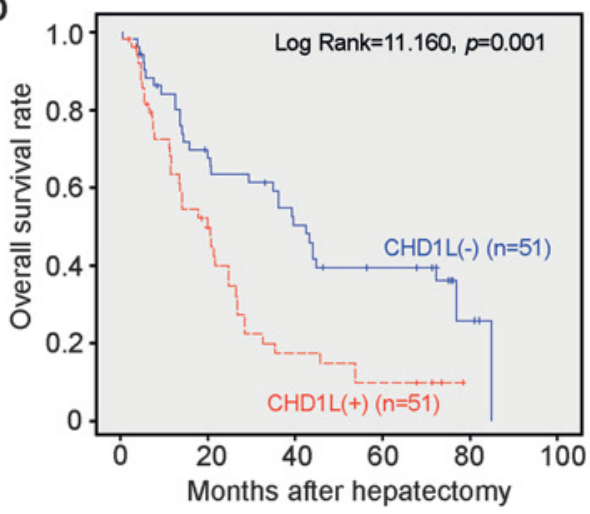

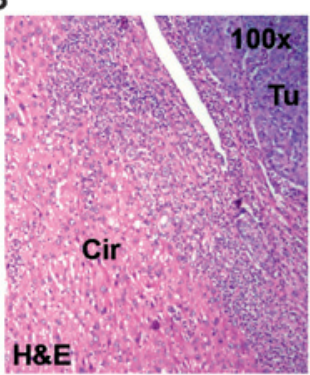
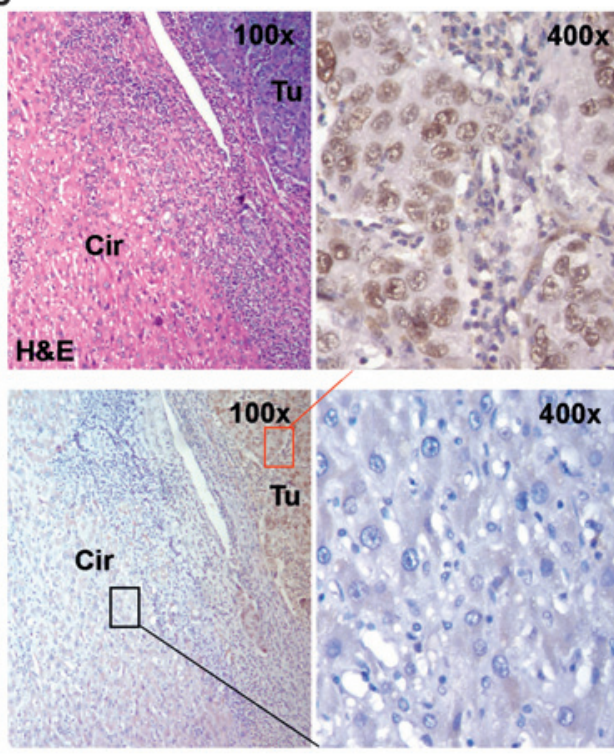

IHC (400x)

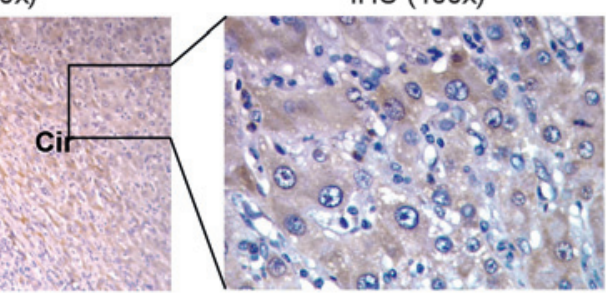

$E$

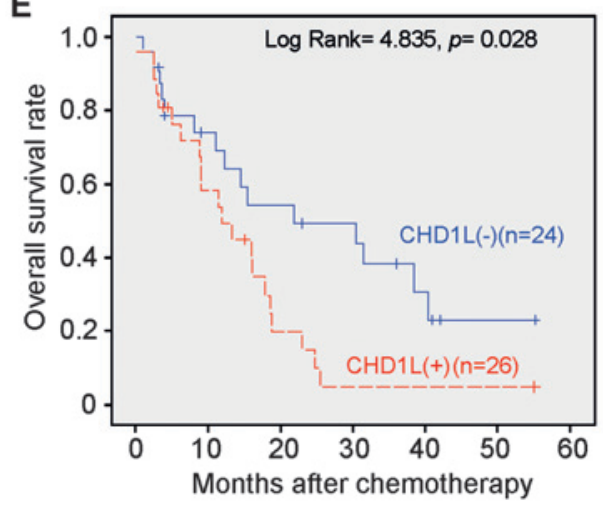


Table 1 Clinicopathological correlation of CHD1L expression in HCC

\begin{tabular}{|c|c|c|c|c|}
\hline \multirow{2}{*}{$\begin{array}{l}\text { Clinicopathological } \\
\text { features }\end{array}$} & \multirow{2}{*}{$\begin{array}{l}\text { Number } \\
(n=109)\end{array}$} & \multicolumn{2}{|c|}{ CHD1L expression } & \multirow[b]{2}{*}{ p Value } \\
\hline & & Without OE & With $\mathrm{OE}$ & \\
\hline \multicolumn{5}{|l|}{ Gender } \\
\hline Male & 95 & 46 & 49 & \\
\hline Female & 14 & 8 & 6 & 0.580 \\
\hline \multicolumn{5}{|l|}{ Age } \\
\hline$\leq 60$ & 88 & 46 & 42 & \\
\hline$>60$ & 21 & 8 & 13 & 0.332 \\
\hline \multicolumn{5}{|l|}{$\mathrm{HbsAg}$} \\
\hline Negative & 12 & 7 & 5 & \\
\hline Positive & 97 & 47 & 50 & 0.556 \\
\hline \multicolumn{5}{|l|}{ Serum AFP (ng/ml) } \\
\hline$\leq 400$ & 55 & 29 & 26 & \\
\hline$>400$ & 54 & 25 & 29 & 0.567 \\
\hline \multicolumn{5}{|l|}{ Tumour size $(\mathrm{cm})^{*}$} \\
\hline$\leq 5$ & 23 & 15 & 8 & \\
\hline$>5$ & 86 & 39 & 47 & 0.103 \\
\hline \multicolumn{5}{|l|}{ Cirrhosis $†$} \\
\hline Absent & 29 & 13 & 16 & \\
\hline Present & 70 & 38 & 32 & 0.508 \\
\hline \multicolumn{5}{|c|}{ Tumour encapsulation $†$} \\
\hline Absent & 41 & 21 & 20 & \\
\hline Present & 58 & 30 & 28 & 1.000 \\
\hline \multicolumn{5}{|c|}{ Microsatellite formation $\dagger$} \\
\hline Absent & 68 & 40 & 28 & \\
\hline Present & 29 & 10 & 19 & 0.045 \\
\hline \multicolumn{5}{|l|}{ Tumour stage (AJCC) } \\
\hline Stage I & 24 & 18 & 6 & \\
\hline Stage II & 63 & 27 & 36 & \\
\hline Stage III & 22 & 9 & 13 & 0.018 \\
\hline
\end{tabular}

*Tumour size was measured by the length of the largest tumour nodule.

†Partial data are not available, and statistics were based on the available data. AFP, $\alpha$-fetoprotein; AJCC, American Joint Committee on Cancer; $\mathrm{HBsAg}$; hepatitis C surface antigen; $\mathrm{HCC}$, hepatocellular carcinoma; $\mathrm{OE}$, overexpression.

Biotechnology (Santa Cruz, California, USA). Western blotting was performed as described previously. ${ }^{10}$

\section{Construction and amplification of recombinant adenovirus vectors}

Replication-incompetent adenoviruses expressing short hairpin RNA (shRNA) were constructed using the BLOCK-iT Adenoviral RNAi Expression System (Invitrogen) according to the manufacturer's instructions. We first designed four pairs of siRNAs based on full-length CHD1L (accession no NM_004284). The sequences that could effectively knock down CHD1L were converted to shRNA sequences by adding hairpin sequences. The isolated adenoviral expression clones were then digested to expose the inverted terminal repeat and then transfected into 293A cells (provided with the kit) using Lipofectamine 2000 (Invitrogen) to generate crude adenoviral stocks. Large-scale amplification of adenoviral vectors was conducted in 293A cells and the titres of the purified virus were determined by standard plaque-forming assay according to the manufacturer's instructions.

\section{Adenoviral infection in vitro}

PLC8024 cells were grown to 80\% confluency. After washing with phosphate-buffered saline (PBS), cells were incubated with adenoviral vectors for $2 \mathrm{~h}$ in DMEM containing 5\% FBS, followed by culturing in complete medium.

Xenograft tumorigenesis and treatment with 5-FU in nude mice PLC8024 cells were used to generate tumours in nude mouse as described previously. ${ }^{13}$ When tumours reached $\sim 5 \mathrm{~mm}$ in diameter, each mouse was then given an intratumoral injection of adenoviral vectors (CHD1L-shRNA or Adv-Lacz) at a dose of $2 \times 10^{9}$ plaque-forming units ( $\mathrm{pfu}$ ) in $20 \mu \mathrm{l}$ of PBS once per week. After the injection of viral vectors, the mice were treated with 5 -FU (40 mg/ $\mathrm{kg}$ body weight; intraperitoneally) or with $20 \mu \mathrm{l}$ of PBS (pH 7.4; intraperitoneally). Tumour growth was assessed by the average volume of tumours as described previously. ${ }^{13}$

\section{Statistical analysis}

The Statistical Package for the Social Sciences, version 16 (SPSS 16.0, SPSS, Chicago, Illinois, USA) was used for data analysis. CHD1L expression levels in tumour tissue and matched nontumour tissue were compared using Wilcoxon signed rank test. The clinicopathological features in CHD1L-positive patients and CHD1L-negative patients were compared using the Pearson $\chi^{2}$ test for categorical variables, and an independent Student t test for continuous data. Kaplan-Meier plots and log rank tests were used for survival analysis. A $p$ value $<0.05$ was considered statistically significant.

\section{RESULTS}

\section{Patient characteristics}

Of the 109 patients (supplementary table 1), 87.1\% were male; the median age was 46 years (range $21-75$ years). Most patients were chronic carriers of hepatitis B virus (89.9\%). The median $\alpha$-fetoprotein value was $71.34 \mathrm{ng} / \mathrm{ml}$ (range $0-210000 \mathrm{ng} / \mathrm{ml}$ ). A total of 102 patients with follow-up data were eligible for overall survival (OS) analysis (seven patients without follow-up data were excluded). The median follow-up time was 24.8 months (95\% CI 17.969 to 31.631). Within 4 years (1.0-45.0 months), 59 patients had developed recurrent HCCs and 50 patients had received about three cycles of TACE treatment (figure 1). These 50 patients were eligible for analyses of $O S$ and the association between CHD1L expression and chemotherapy outcome.

\section{Overexpression of CHD1L is associated with microsatellite} tumour formation, advanced stage and poor prognosis in HCC To determine the prevalence and clinical significance of CHD1L in HCC, the correlation between CHD1L overexpression and the clinicopathological features was investigated in a retrospective cohort of 109 HCC cases by IHC. In the 109 cases examined, CHD1L overexpression was detected in $50.5 \%$ (55/109) of HCC tissues (figure 2A and supplementary table 2). Expression of CHD1L was significantly stronger in tumour tissues than adjacent non-tumour tissues ( $<<0.001$; Wilcoxon signed rank test). Furthermore, liver cirrhosis was obviously observed at the peritumoral area in $56.9 \%(62 / 109)$ of HCC specimens. In the

Table 2 The association between CHD1L overexpression and tumour response to chemotherapy in 50 patients with HCC

\begin{tabular}{lclll}
\hline Parameters & $\begin{array}{l}\text { Number } \\
(\mathbf{N}=\mathbf{5 0})\end{array}$ & $\begin{array}{l}\text { CHD1L negative } \\
(\mathbf{N}=\mathbf{2 4})(\%)\end{array}$ & $\begin{array}{l}\text { CHD1L positive } \\
(\mathbf{N}=\mathbf{2 6})(\%)\end{array}$ & $\mathbf{p}$ Value \\
\hline Response $^{*}$ & & & & \\
$\quad$ Complete response & 0 & 0 & 0 & \\
$\quad$ Partial response (PR) & 11 & 8 & 3 & \\
$\quad$ Stable disease (SD) & 9 & 6 & 3 & \\
$\quad$ Progressive disease (PD) & 30 & 10 & 20 & 0.020 \\
2-year survival rate $\dagger$ & & $9 / 24(37.5 \%)$ & $2 / 26(7.7 \%)$ & \\
3-year survival rate $\dagger$ & & $7 / 24(29.2 \%)$ & $1 / 26(3.9 \%)$ & \\
Median 0S (months) $\dagger$ & & $21.9(1.0-44.1)$ & $11.9(5.4-18.4)$ & 0.028 \\
\hline
\end{tabular}

*The tumour response was evaluated using the Response Evaluation Criteria in Solid Tumors (RECIST) described in the Materials and methods section.

†Overall survival (OS), 2-year and 3-year survival rate were calculated from the data of the first treatment, using the Kaplan-Meier method. 
peritumoral cirrhotic tissues, absent, weak or moderate expression of CHD1L was observed in $37.1 \%(23 / 62), 43.5 \%(27 / 62)$ or $19.4 \%(12 / 62)$ of HCC cases, respectively (figure $2 \mathrm{~B}$ and supplementary table 3 ). Expression of CHD1L was significantly higher in tumour tissues than in the corresponding peritumoral cirrhotic tissues $(p<0.001$; Wilcoxon signed rank test). Interestingly, CHD1L was expressed in the cytoplasm of hepatocytes in cirrhotic tissues (figure 2C). The correlation analysis (Peason $\chi^{2}$ test) showed that CHD1L overexpression in HCC tumours was significantly associated with tumour microsatellite tumour formation $(p=0.045)$ and advanced tumour stage $(p=0.018$, table 1). The prognostic significance of CHD1L overexpression was also studied in this cohort of 102 patients with valid follow-up data. The results showed that CHD1L overexpression was significantly associated with poorer OS of patients (log rank $=11.160, p=0.001$; figure $2 \mathrm{~B}$ ). The 5 -year survival rate dropped from $31.4 \%(16 / 51)$ in patients without CHD1L ovexpression (defined as 'CHD1L negative') to $7.8 \%$ (4/51) in patients with CHD1L overexpression (defined as 'CHD1L positive'). The median OS times in CHD1L-negative $(n=51)$ and CHD1L-positive $(n=51)$ subgroups of HCC patients were 42.6 months (95\% CI 35.1 to 50.1 ) and 19.8 months (95\% CI 12.6 to 27.0), respectively. These data indicated that CHD1L could be a potential prognostic marker to predict the OS of patients with HCC.

\section{Overexpression of CHD1L correlates with the poorer outcome of chemotherapy}

The effect of CHD1L overexpression on chemotherapy was further studied in 50 patients with recurrent HCC in this cohort. They had received TACE treatment with the chemotherapeutic drugs 5-FU in combination with DOX and CDDP. Tumour response to chemotherapy and OS time were calculated from the date of the first treatment. Among these patients with HCC, 30/50 (60\%) of them developed progressive disease during chemotherapy and were classified as the 'chemoresistant' group. In the remaining 20 patients, partial response and stable diseases were observed in 11 and 9 cases, respectively, and they were defined as the 'chemosensitive' group (table 2). IHC results showed that the frequency of CHD1L overexpression was significantly higher in the 'chemoresistant' group (20/30, 66.7\%) than that in the 'chemosensitive' group $(6 / 20,30 \%, p=0.02$, Pearson $\chi^{2}$ test, table 2). As shown in figure $2 \mathrm{C}$, overexpression of CHD1L was also significantly correlated with OS time of patients with HCC who received chemotherapy (log rank=4.835, $p=0.028$ ). The 2-year and 3-year survival rate dropped from $37.5 \%$ and $29.2 \%$ in patients with CHD1L-negative HCC to $7.7 \%$ and $3.9 \%$ in those with CHD1L-positive HCC, respectively (table 2). In addition, the median OS time in CHD1L-negative $(n=24)$ and CHD1L-positive $(n=26)$ subgroups of patients with HCC were 21.9 months (95\% CI 1.0 to 44.1 )
Figure 3 The inhibitory effect of CHD1L on 5-fluorouracil (5-FU)-induced apoptosis. (A) The expression of CHD1L was detected by western blot analysis in CHD1L-transfected (CHD1L-C3 and CHD1L-C6), parental (QGY-7703) and empty vector-transfected cells (Vec7703). (B, C) Cell viabilities of CHD1LC3, CHD1L-C6 and Vec-7703 cells were detected by XTT proliferation assay after treatment with 5 -FU $(B)$ or doxorubicin (DOX) (C) at the indicated concentrations for $48 \mathrm{~h}$. Data represent the mean $\pm S D$ derived from three independent experiments with triplicate wells $\left({ }^{*} p<0.05 ;{ }^{* *} p<0.01\right)$. (D) After treatment with 5 -FU $(25 \mu \mathrm{g} / \mathrm{ml})$ or DOX (400 ng/ml) for $48 \mathrm{~h}$, the apoptotic index was determined by TUNEL

(deoxyribonucleotidyl transferase (TDT)-mediated dUTP-digoxigenin nick end labelling) assay. The upper panel shows the representative images of the TUNEL assay. The apoptotic cells were stained with fluorescein isothiocyanate (FITC)-labelled DNA strand breaks (green signals). The nuclei were counterstained by 4',6-diamidino-2phenylindole (DAPI). The apoptotic index was calculated and is summarised in the bar chart (lower panel). Data represent the mean $\pm S D$ derived from three independent experiments in triplicate $\left({ }^{*} \mathrm{p}<0.01 ;{ }^{* *} \mathrm{p}<0.001\right)$.

(E) After treatment with 5-FU or DOX for the indicated times, the cleavages of caspase 3 and PARP (poly(ADP-ribose) polymerase) was detected in CHD1L-C3 and Vec-7703 cells by western blot analysis.

$\beta$-Actin was used as a loading control.
A

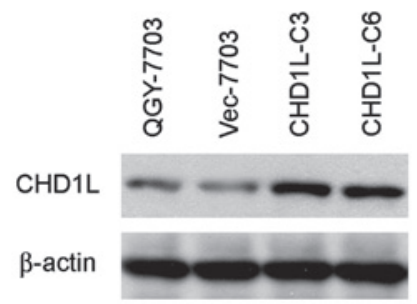

B
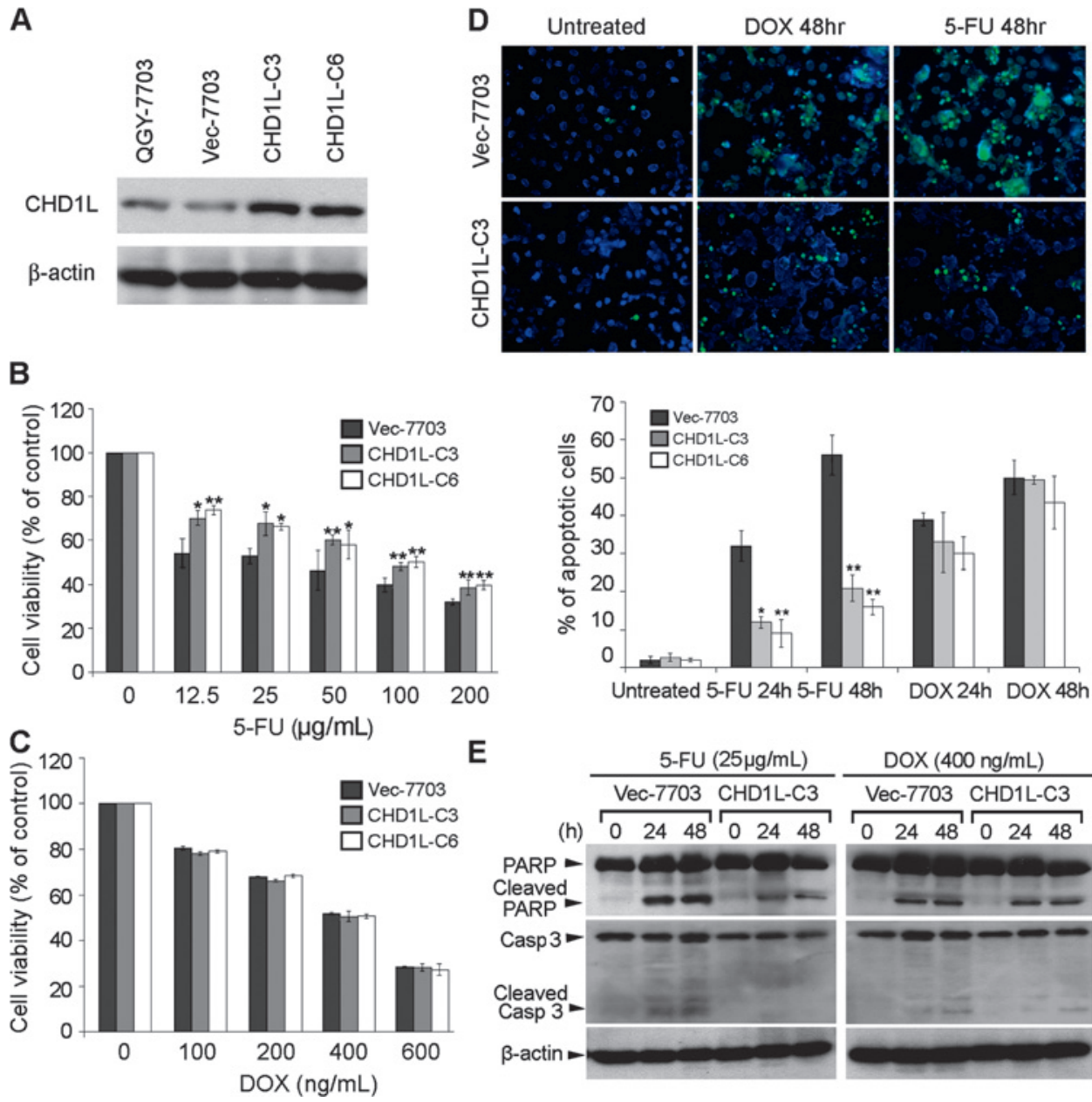

E

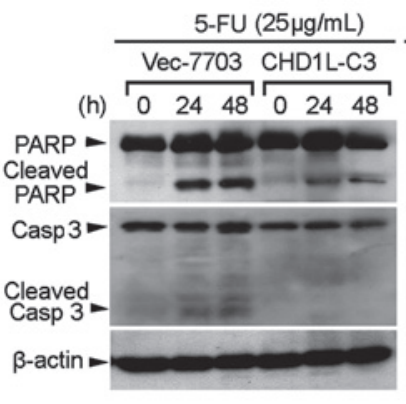

$\mathrm{DOX}(400 \mathrm{ng} / \mathrm{mL})$

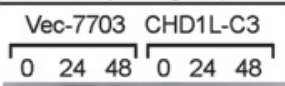

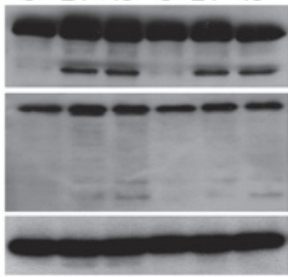


and 11.9 (5.4-18.4) months (95\% CI 9.2 to 30.4 ), respectively (table 2).

\section{CHD1L inhibits cell apoptosis in HCC cells induced by 5-FU, but not DOX}

Since overexpression of CHD1L was significantly associated with the poor outcomes of chemotherapy in patients with HCC, we further investigated the inhibitory effect of CHD1L on two conventional chemotherapeutic agents, 5-FU and DOX. For this purpose, CHD1L expression plasmid or empty vector was stably transfected into a HCC cell line QGY-7703 as described previously. ${ }^{12}$ Elevated expression of CHD1L was confirmed in two CHD1L transfectants (CHD1L-C3 and CHD1L-C6) by western blot analysis (figure 3A). CHD1L-7703- and empty vector-transfected (Vec-7703) cells were then exposed for $72 \mathrm{~h}$ to varying concentrations of $\operatorname{DOX}(0,100,200,400,500$ and $600 \mathrm{ng} / \mathrm{ml} ; \mathrm{IC}_{50}$ at $\left.400 \mathrm{ng} / \mathrm{ml}\right)$ and 5 -FU $(0,12.5,25,50,100$ and $200 \mu \mathrm{g} / \mathrm{ml} ; \mathrm{IC}_{50}$ at $\left.25 \mu \mathrm{g} / \mathrm{ml}\right)$. The XTT proliferation assay showed that CHD1L-7703 (C3 and C6) cells were more viable compared with Vec-7703 cells after 5-FU treatment (figure 3B). However, no obvious difference in cell viability was observed between CHD1L-7703 and Vec-7703 cells when cells were treated with DOX (figure 3C).

Next, we studied whether the preferential survival of CHD1L transfectants after exposure to 5 -FU was attributed to low rates of apoptosis. After the treatment with 5-FU, the apoptotic cells were detected by TUNEL assay. The apoptotic index, obtained by counting the percentage of TUNEL-positive cells, was compared between CHD1L-7703 and Vec-7703 cells. The apoptotic index of Vec-7703 cells increased rapidly after the treatment with $5-\mathrm{FU}$, reaching $>57 \%$ after $48 \mathrm{~h}$ of exposure to 5 -FU (figure 3D). In contrast, the apoptotic index of CHD1L7703 cells was significantly lower at every time point in the presence of 5-FU. However, after DOX treatment, there was no dramatic difference in the apoptotic index between CHD1L-7703 and Vec-7703 cells (figure 3D). To confirm this finding, activation of caspase 3 and PARP, which are two typical characteristics of cell apoptosis, was investigated by western blot analysis in Vec-7703 and CHD1L-C3 cells. As seen in figure 3E, the cleaved caspase 3 and PARP were dramatically decreased in CHD1L-C3 cells compared with Vec-7703 cells after 5-FU treatment. However, no notable difference was detected between CHD1LC3 and Vec- 7703 cells when cells were treated with DOX. These data suggest that $C H D 1 L$ could inhibit the apoptotic progression of HCC cells upon 5-FU stimulation, but not DOX stimulation.

\section{CHD1L confers chemoresistance by inhibiting the Nur77/Cyto c/caspase 9 pathway}

Our previous study demonstrated that CHD1L is able to block nuclear to mitochondrial translocation of Nur77 via their interaction, and subsequently to inhibit Cyto $c$ release into the cytoplasm and the following activation of caspase 9 and caspase 3 , finally inhibiting apoptosis. ${ }^{12}$ Based on these findings, we investigated whether the inhibitory effect of CHD1L on 5-FU is
A
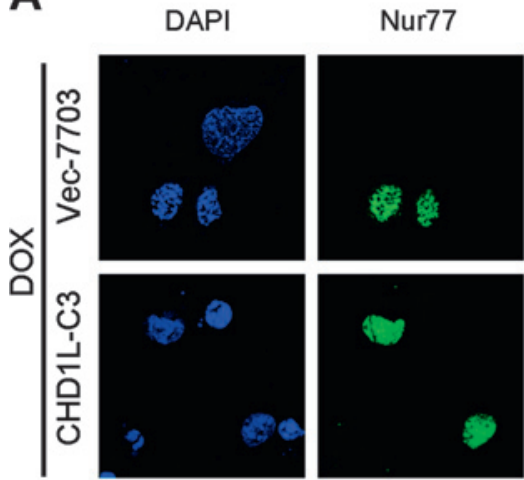

B

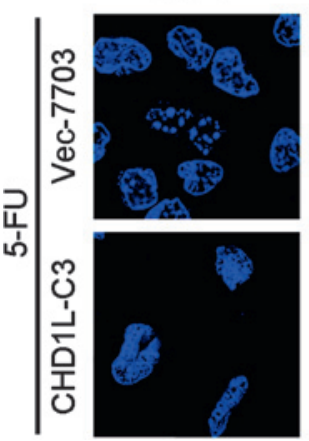

Nur77

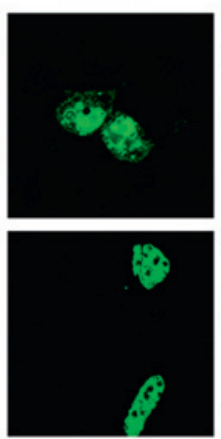

Mitotracker

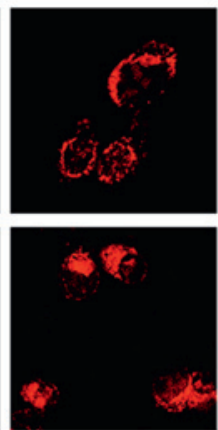

Mitotracker

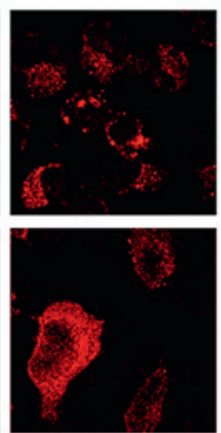

C

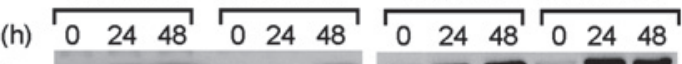

Overlay
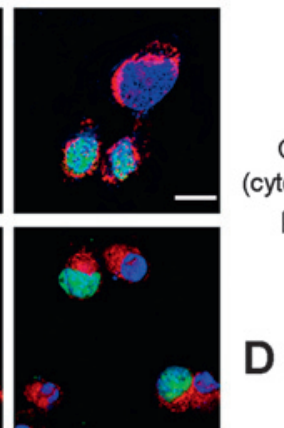

D
Cyto $c$ (cytoplasma) $\beta$-actin

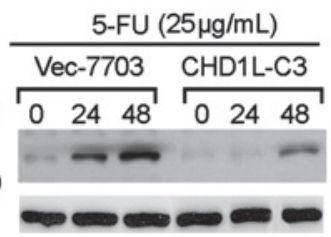

5 -FU $(25 \mu \mathrm{g} / \mathrm{mL})$

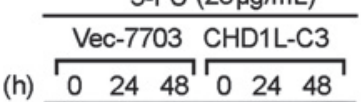

Pro-Casp 9 Overlay

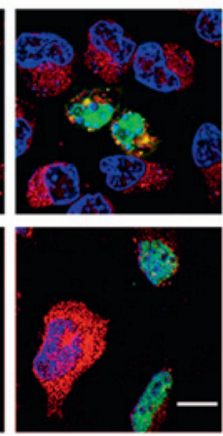

Cleaved Casp 9 Pro-Casp 8

DOX $(400 \mathrm{ng} / \mathrm{mL})$ m-

Figure 4 CHD1L inhibits Nur77-mediated apoptosis induced by 5-fluorouracil (5-FU), but not by doxorubicin (DOX). (A and B) After treatment with DOX (400 ng/ml) (A) or 5-FU (25 $\mathrm{g} / \mathrm{ml})$ (B) for $24 \mathrm{~h}, \mathrm{GFP} /$ Nur77 (green), mitochondria (red) and nuclei (blue) were captured using confocal microscopy. Both Vec-7703 and CHD1L-C3 cells showed an exclusively nuclear localisation of Nur77 after treatment with D0X. However, after treatment with 5-FU, Nur77 in Vec-7703 cells, but not in CHD1L-C3 cells, began to migrate from the nucleus to the mitochondria (bar=10 $\mu \mathrm{m}$ ). $(C$ and D) The level of cytochrome $c$ (Cyto $c$ ) in the cytosolic fraction (C), and expression of caspase 9 and 8 (D) in Vec-7703 and CHD1L-C3 cells were detected by western blotting after 5-FU or DOX treatment at the indicated time points. $\beta$-Actin was used as a loading control. DAPI, 4',6-diamidino-2-phenylindole. 
associated with the Nur77/Cyto c/caspase 9 pathway. For this purpose, the GFP/Nur77 expression plasmid was transiently transfected into Vec-7703 and CHD1L-C3 cells, which were then treated with 5-FU or DOX. The subcellular location of Nur77 was detected by confocal microscopy. When treated with DOX for $24 \mathrm{~h}$, apoptosis (characterised as nuclear condensation and fragmentation) occurred in Vec-7703 and CHD1L-7703 cells transfected with GFP/Nur77 (figure 4A). In both Vec-7703 and CHD1L-C3 cells, GFP/Nur77 was exclusively localised in the nucleus after DOX treatment, suggesting that apoptosis induced by DOX was not through the Nur77-mediated apoptotic pathway. However, the nuclear to mitochondrial translocation
Figure 5 Adenoviral CHD1L-shRNAs (short hairpin RNAs) inhibits tumorigencity and chemoresistance in vitro. (A and B) Knockdown efficiency of CHD1L-shRNAs (CHD1L-shRNA1 and CHD1L-shRNA2) was detected by quantitiative PCR (A) or western blot analysis (B) in PLC8024 cells. Cells were infected with CHD1L-shRNAs at the indicated concentrations or with the negative control (Adv-Lacz). For quantitative PCR, three independent experiments were performed in triplicate. $\beta$-Actin was used as a loading control for western blot analysis. (C) Representative images of the inhibitory effect of CHD1L-shRNAs on foci formation in PLC8024 cells (left panel) compared with parental cells and Adv-Lacz-infected cells. Surviving colonies (>50 cells/colony) were counted and are shown in a bar chart (right panel). Data represent the mean $\pm S D$ derived from three independent experiments with triplicate wells $\left({ }^{*} p<0.01 ;{ }^{* *} p<0.001\right)$.

(D) Representative images of colony formation in soft agar (left panel). The numbers of colonies ( $\geq 10$ cells) were counted and are summarised in a bar chart (right panel). Data represent the mean $\pm S D$ derived from three independent experiments with triplicate wells $\left({ }^{* *} p<0.001\right)$. (E) Effects of CHD1L-shRNAs on the growth rate in PLC8024 cells. Growth curves of cells infected by adenoviral vectors (at a multiplicity of infection (MOI) of 2) were detected for 6 days by XTT proliferation assay. Data represent the mean $\pm S D$ derived from three individual experiments with triplicate wells $\left({ }^{*} p<0.001\right)$. (F) The inhibitory effect of CHD1L-shRNAs on chemoresistance to 5-fluorouracil (5-FU). After CHD1LshRNA (MOI=10) infection, PLC8024 cells were treated with 5 -FU for $48 \mathrm{~h}$ at the indicated concentration. The cell viabilities were detected by XTT assay. Compared with Adv-Lacz, CHD1LshRNAs could significantly inhibit the chemoresistance to 5 -FU $\left({ }^{*} \mathrm{p}<0.05\right.$; $\left.{ }^{* *} \mathrm{p}<0.01\right)$. Three independent experiments were performed in triplicate. of Nur77 was observed in Vec-7703 cells after 5-FU treatment (figure 4B), suggesting that the proapoptotic effect of 5-FU was via the Nur77-mediated apoptotic pathway. As expected, CHD1L could inhibit nuclear to mitochondrial translocation of Nur77 and the translocation was not observed in CHD1L-C3 cells after 5-FU treatment (figure 4B). The effects of CHD1L on Cyto $c$ release into the cytoplasm and the activation of caspase 9 were then studied by western blot analysis. Compared with Vec-7703 cells, the levels of Cyto $c$ in the cytoplasm and of cleaved caspase 9 were obviously decreased in CHD1L-C3 cells after 5-FU treatment (figure 4C,D). However, CHD1L had no effect on Cyto $c$ release and the activation of caspase 9
A

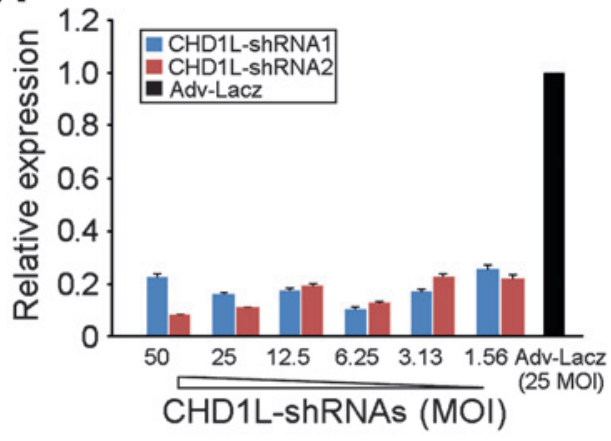

B

C
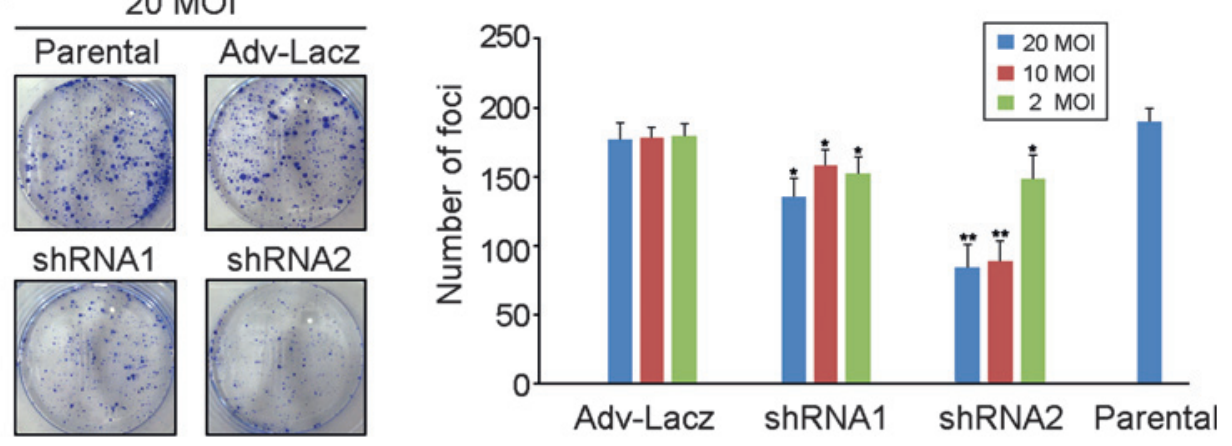

D
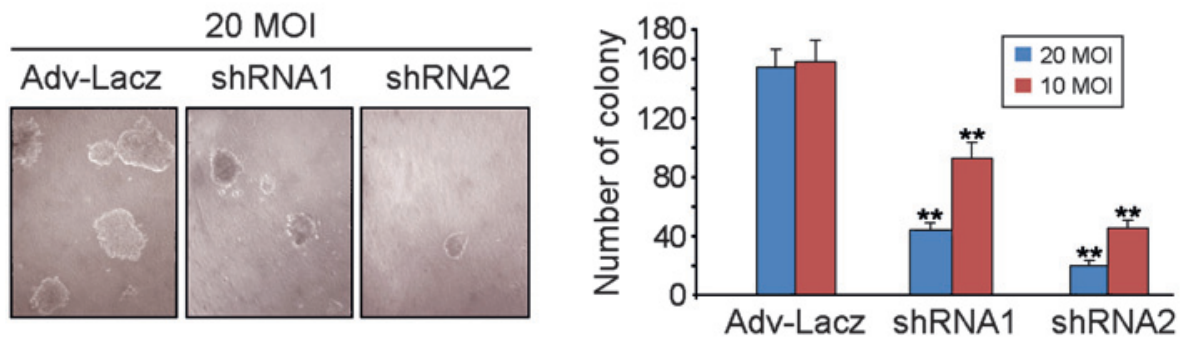

E

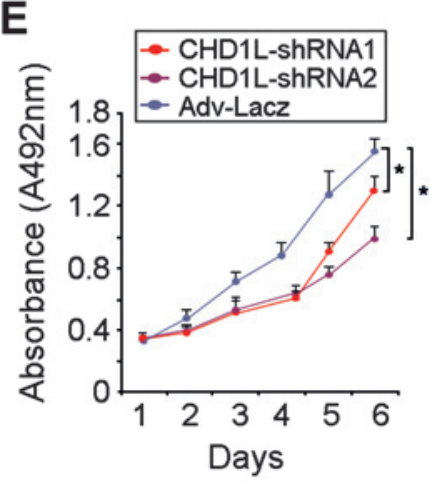

$\mathbf{F}$

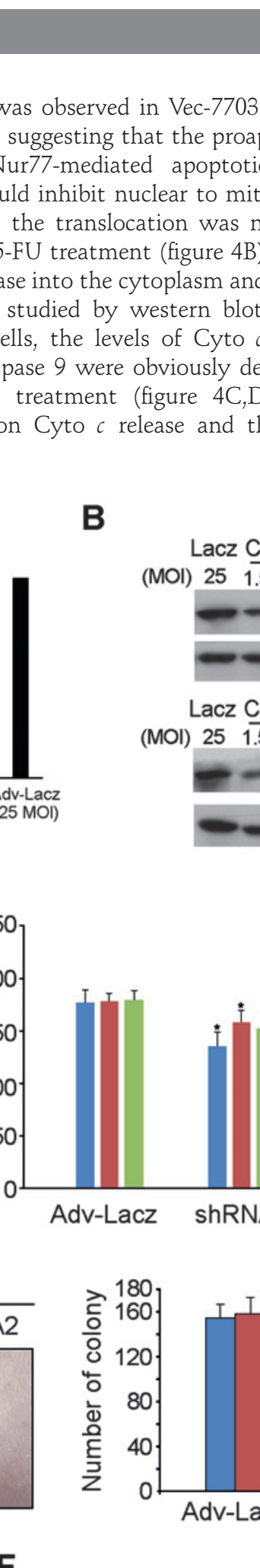


when Vec-7703 and CHD1L-7703 cells were treated with DOX (figure 4C,D). Western blot analysis of 5-FU- or DOX-induced caspase 8 activation indicated that the antiapoptotic effect of CHD1L on 5-FU or DOX treatment was not associated with the death signalling pathway. All these data suggested that CHD1L could inhibit apoptosis induced by 5-FU, rather than DOX, via the inhibition of the Nur77-mediated apoptotic pathway and confer chemoresistance to 5 -FU.

\section{Virus-mediated CHD1L silencing suppresses the tumorigenic ability of CHD1L and chemoresistance to 5-FU}

To study further the tumorigenic and chemoresistant effects of CHD1L in HCC, two shRNAs against CHD1L were cloned into the pENTR/U6 vector for adenovirus vector construction (CHD1L-shRNA1 and CHD1L-shRNA2), and Adv-Lacz was included as a negative control. To test the efficiency of inhibition by CHD1L-shRNAs on the expression of CHD1L in PLC8024 cells, cells were infected with various concentrations of virus ranging from a multiplicity of infection (MOI) of 1.5 to 50. Realtime quantitative PCR and western blot analyses showed that CHD1L-shRNAs could efficiently silence CHD1L expression at both the mRNA and protein levels (figure $5 \mathrm{~A}, \mathrm{~B}$ ). In vitro assays were then used to investigate the inhibitory effects of CHD1LshRNAs on tumorigenicity in the HCC cell line PLC8024.
Compared with Adv-Lacz-infected cells, CHD1L-shRNAinfected cells showed a lower efficiency of foci formation $(p<0.01$, independent Student $t$ test, figure $5 C)$. Similarly, the colony formation in soft agar was significantly reduced in CHD1L-shRNA-infected cells compared with Adv-Lacz-infected cells $(p<0.001$, independent Student $t$ test, figure 5D). Next, XTT proliferation assays showed that after viral infection, the growth rate of PLC8024 cells was significantly inhibited by CHD1L-shRNAs $(p<0.001$, independent Student $t$ test; figure $5 \mathrm{E})$. Importantly, after viral infection followed by treatment with 5-FU at different concentrations (0, 10, 25, 50, 100 and $150 \mu \mathrm{g} / \mathrm{ml}$; $\mathrm{IC}_{50}$ at $75 \mu \mathrm{g} / \mathrm{ml}$ ) for $72 \mathrm{~h}$, the cell viability was significantly inhibited by CHD1L-shRNA-treated cells when compared with Adv-Lacz-infected cells $(p<0.05$, independent Student $t$ test; figure $5 \mathrm{~F}$ ).

\section{Virus-mediated CHD1L silencing inhibits tumorigenesis and increases chemosensitivity to $\mathbf{5 - F U}$ in nude mice}

To explore the effect of CHD1L-shRNA in vivo, xenograft tumours were generated by injecting PLC8024 cells subcutaneously into nude mice. When the xenograft tumours reached $\sim 5 \mathrm{~mm}^{3}$, each group of mice (5 mice per group) was given CHD1L-shRNA1 or Adv-Lacz (intratumoral injection, $2 \times 10^{9}$ plaque-forming units (pfu), once a week for 6 weeks), combined
Figure 6 CHD1L depletion by adenoviral CHD1L-shRNAs (short haipin RNAs) inhibits tumorigenicity and increases the chemosensitivity to 5 -fluorouracil (5-FU) in vivo.

(A) Representative images of xenograft tumours in nude mice induced by PLC8024 cells. Left column, before treatment; middle column, 6 weeks after treatment with adenoviral vectors (intratumoral injection, $2 \times 10^{9}$ plaqueforming units, once a week for 6 weeks) combined with 5-FU (intraperitoneal injection, $40 \mathrm{mg} / \mathrm{kg}$ body weight, once a week for 6 weeks) or phosphatebuffered saline (PBS); right column. representative of tumours excised from mice after 6 weeks of treatment. (B) The tumour growth curve of each group of mice which received the scheduled treatment as described above $\left(n=5,{ }^{* *} p<0.0001\right)$. (C-E)

Immunohistochemical staining of CHD1L (C) and proliferating cell nuclear antigen (PCNA) (D) and TUNEL

(deoxyribonucleotidyl transferase (TDT)-mediated dUTP-digoxigenin nick end labelling) assay (E) were performed on serial sections of xenograft tumours excised from mice after 6 weeks of treatment. Arrows indicate the strong nuclear expression of PCNA (D) and TUNEL-positive cells (E).
A
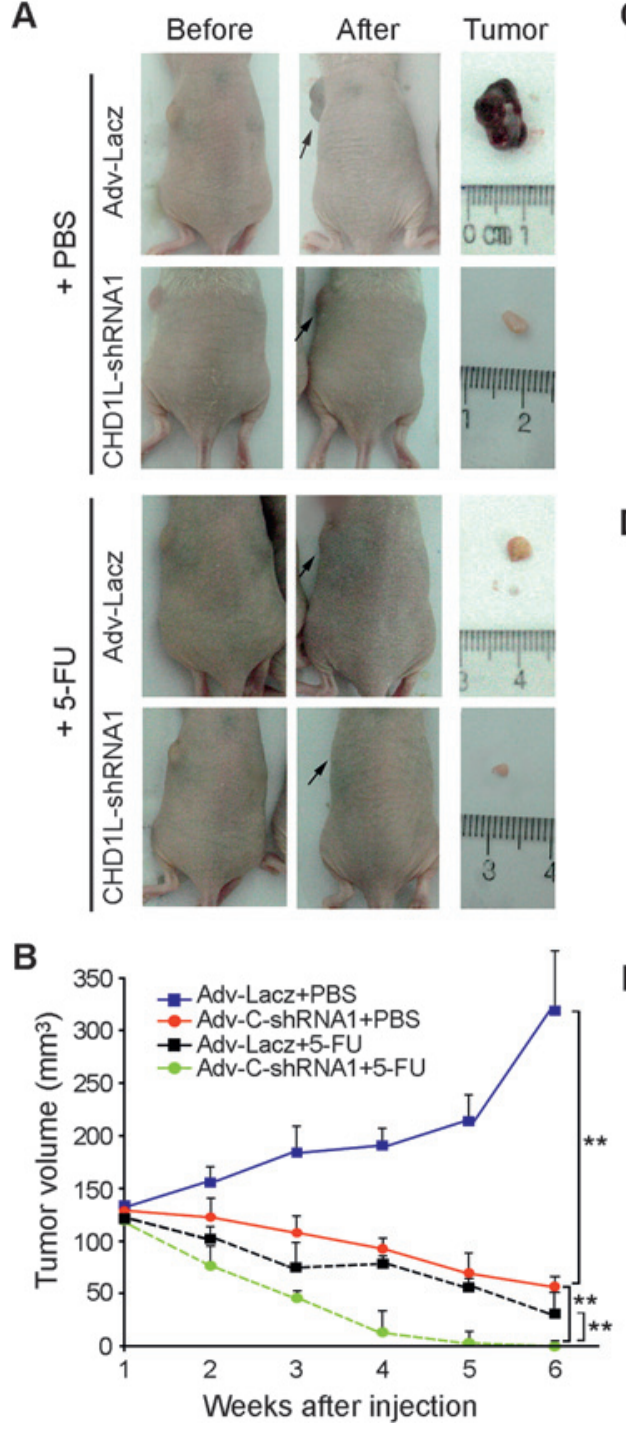

E

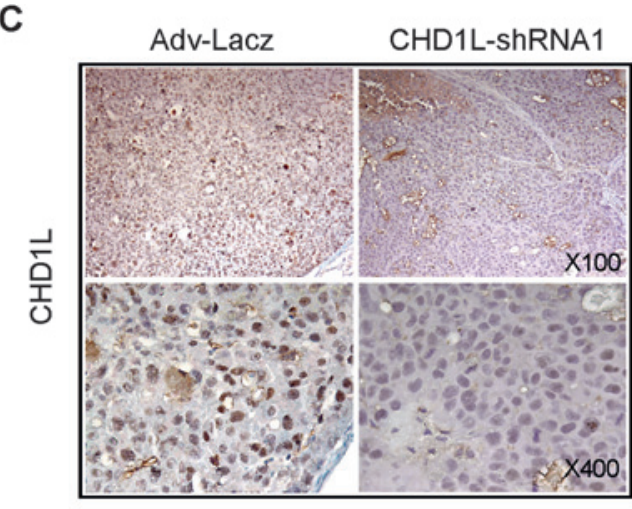

D
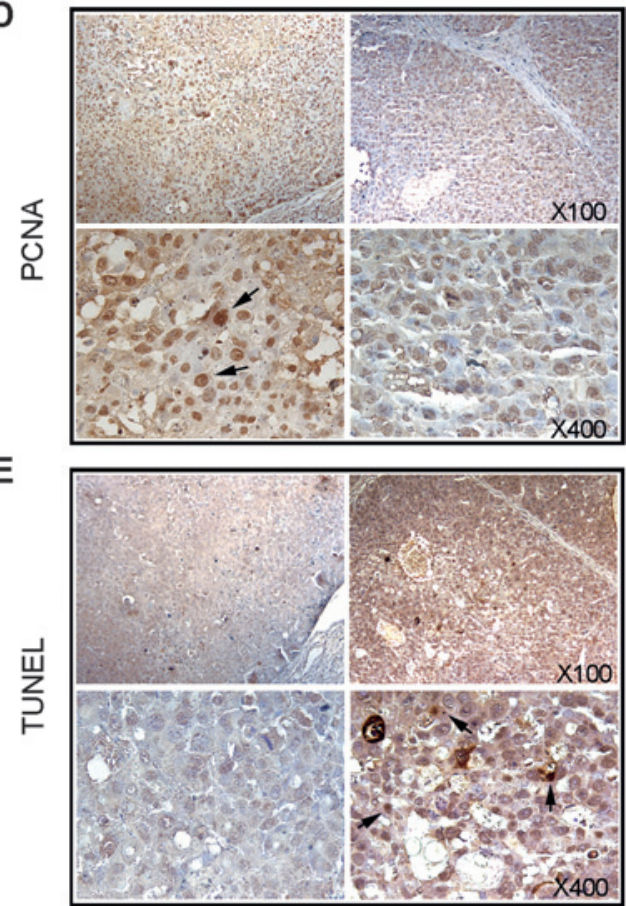
with 5-FU (intraperitoneal injection, $40 \mathrm{mg} / \mathrm{kg}$ body weight, once a week for 6 weeks) or PBS. Compared with the Adv-Lacz/ PBS group, tumour growth rates and tumour volumes were significantly inhibited in the three other groups (figure 6A,B). Upon intraperitoneal treatment with $\mathrm{PBS}$, the average tumour volume of the harvested xenograft tumours from the CHD1LshRNA1 group $\left(55 \pm 12 \mathrm{~mm}^{3}\right)$ was significantly smaller than tumours from the Adv-Lacz group $\left(320 \pm 65 \mathrm{~mm}^{3}, p<0.0001\right.$, independent Student t test). Interestingly, the inhibitory effect of CHD1L-shRNA1 on tumour growth was similar to that of 5 -FU treatment (figure 6B). Furthermore, when mice were treated with the combination of CHD1L-shRNA1 and 5-FU, the tumour growth was significantly inhibited compared with mice treated with either CHD1L-shRNA1 or 5-FU $(p<0.0001$; independent Student t test, figure $6 \mathrm{~B}$ ). In $3 / 5$ of mice treated with CHD1L-shRNA1 and 5-FU, the tumour had completely disappeared after 6 weeks.

To investigate further the effect of CHD1L-shRNA1 on the chemosensitivity to 5-FU in vivo, immunohistochemical staining of proliferating cell nuclear antigen (PCNA) and CHD1L, as well as TUNEL assay were performed to detect the proliferating and apoptotic cells on serial sections of xenograft tumours from 5-FU-injected mice. The results showed that the endogenous expression of CHD1L was apparently decreased in CHD1L-shRNA1-treated tumours compared with Adv-Laczinjected tumours (figure 6C). As expected, fewer PCNA-positive (figure 6D) and more TUNEL-positive cells (figure 6E) were observed in tumours treated with CHD1L-shRNA1, compared with Adv-Lacz-treated tumours. All these data suggested that silencing endogenous CHD1L expression by virus-mediated RNA interference (RNAi) might inhibit the tumorigenicity and increase the chemosensitivity to 5 -FU.

\section{DISCUSSION}

HCC is a major health problem worldwide because of its extremely poor prognosis. The high mortality rate for HCC is due to the limited treatment options. Potential curative treatments including liver resection, transplantation and percutaneous ablation are available for early-stage HCC, which accounts for $30-40 \%$ of all HCC cases. ${ }^{16-18}$ TACE is the recommended first-line non-curative treatment for patients with large multifocal inoperable $\mathrm{HCC}^{19}$ because it has been shown to have survival benefits in recent randomised controlled trials. ${ }^{20} 21$ Although chemotherapy can improve the survival rate for advanced HCC cases, chemoresistance remains a tremendous therapeutic challenge in treating HCC. ${ }^{16} 2223$ The efficacy of chemotherapeutic drugs is generally believed to depend on their ability to trigger apoptosis. ${ }^{4} 5$ Therefore, identification and characterisation of genes correlated with chemoresistance is imperative to understand the molecular mechanism of chemoresistance in HCC and find new therapeutic targets for HCC treatment.

Amplification of 1q21 is an early event in HCC development, ${ }^{24}$ implying that the putative oncogene within this region may play an important role in the initiation of HCC pathogenesis. In our previous studies, we isolated a candidate oncogene $C H D 1 L^{10}$ and demonstrated that its oncogenic function is associated with its antiapoptotic role. ${ }^{12}$ In the present study, HCC tissues showed increased expression of CHD1L compared with non-tumour (including cirrhotic) tissues in all 109 cases examined. Overexpression of CHD1L was significantly associated with tumour microsatellite formation, advanced tumour stage and shorter OS time. In addition, overexpression of CHD1L was also significantly associated with poor response to chemotherapy in 50 patients with HCC who received the TACE treatment with 5-FU in combination with DOX and CDDP. As reported previously, CHD1L could confer strong resistance to apoptosis by inhibiting Nur77-mediated apoptosis. ${ }^{12}$ These findings provide us with new insights into the clinical value of CHD1L and its role in drug resistance in HCC. The role of CHD1L as an indicator and target in chemosensitivity was further investigated in this study. The results showed that CHD1L could confer drug resistance against chemotherapeutic agents, such as 5-FU, that induce apoptosis through the Nur77-mediated pathway. However, CHD1L fails to confer chemoresistance to agents such as DOX, that induce apoptosis through other pathways. Interestingly, it has been reported that the administration of 5-FU does not significantly benefit patients with $\mathrm{HCC}^{25}$ and a clinical study indicated that patients with HCC treated with 5-FU had a lower 2-year survival rate than patients treated with DOX. ${ }^{14}$ Taken together, these data demonstrate that the overexpression of CHD1L is one of the major mechanisms of chemoresistance to 5-FU in HCC treatment.

Given that CHD1L is frequently overexpressed in HCC, CHD1L may become a useful new therapeutic target in HCC treatment. DNA vector-based shRNA as a means of RNAi is a promising mechanism for the precise disruption of gene expression to achieve a therapeutic effect. However, the clinical usage of shRNA therapeutics in cancer is limited by ineffective delivery into target cancer cells. The viral delivery of shRNAs has been reported to be used for tumour-specific gene therapy to reverse the oncogenic phenotype of cancer cells. ${ }^{26}$ Adenoviral vectors can efficiently transduce genes into a broad range of cell types and have been used extensively as gene delivery vehicles. ${ }^{27}$ In recent years, adenoviral vectors carrying shRNA expression cassettes have been developed and tested in several studies. ${ }^{28-30}$ In this study, we generated Adv-CHD1L-shRNAs and tested the therapeutic efficacy of this viral construct in a HCC cell line PLC8024 in vitro and in vivo. We found that this viral construct could significantly inhibit the endogenous expression of CHD1L in vitro. Further studies indicated that Adv-CHD1L-shRNAs were able to suppress cell growth, clonogenicity and chemoresistance to $5-\mathrm{FU}$ in vitro. More interestingly, in vivo studies showed that Adv-CHD1L-shRNAs could inhibit xenograft tumour growth and increase the sensitivity to 5-FU. The inhibitory efficiency of CHD1L-shRNA is similar to 5-FU treatment. The combination of CHD1L-shRNA and 5-FU showed a significant inhibitory effect on tumour growth in nude mouse compared with the treatment with either CHD1L-shRNA or 5-FU alone. In addition, complete tumour disappearance was observed in 3/5 tested mice. These data strongly suggest that silencing CHD1L expression in $\mathrm{HCC}$ by the corresponding shRNA has a great therapeutic potential in HCC treatment, especially to increase the chemosensitivity combined with chemotherapy.

Funding This work was supported by a Hong Kong Research Grant Council Grant (HKU 7656/07M). Hong Kong RGC Collaborative Research Grants (HKU5/CRF/08 and HKU 7/CRG09), the 'Hundred Talents Program' at Sun Yat-Sen University (85000-3171311) and grants from the National Natural Science Foundation of China (30772475) and the National Key Sci-Tech Special Project of Infectious Diseases (Grant 2008ZX10002-022).

\section{Competing interests None.}

Ethics approval The studies using human tissue were reviewed and approved by the Committees for Ethical Review of Research involving Human Subjects at the University of Hong Kong and the Cancer Center of Sun Yat-Sen University, China.

Contributors LC, THMC, YL and B-JZ performed the majority of the experiments, analysed the data and prepared the manuscript. Y-FY and JH collected clinical 
samples, analysed the clinico-pathological features and performed statistical analysis. $X-Y G$ and $Y-F Y$ supervised the project and provided suggestions. LC and X-YG drafted and revised the manuscript. All authors reviewed, critiqued and offered comments on the text and approved the final version of manuscript.

Provenance and peer review Not commissioned; externally peer reviewed.

\section{REFERENCES}

1. McGlynn KA, Tarone RE, El-Serag HB. A comparison of trends in the incidence of hepatocellular carcinoma and intrahepatic cholangiocarcinoma in the United States. Cancer Epidemiol Biomarkers Prev 2006;15:1198-203.

2. Yeo W, Mok TS, Zee B, et al. A randomized phase III study of doxorubicin versus cisplatin/interferon alpha-2b/doxorubicin/fluorouracil (PIAF) combination chemotherapy for unresectable hepatocellular carcinoma. J Natl Cancer Inst 2005;97:1532-8.

3. Greten TF, Papendorf F, Bleck JS, et al. Survival rate in patients with hepatocellular carcinoma: a retrospective analysis of 389 patients. Br J Cancer 2005:92:1862-8.

4. Blandino G, Levine AJ, Oren M. Mutant p53 gain of function: differential effects of different p53 mutants on resistance of cultured cells to chemotherapy. Oncogene 1999:18:477-85.

5. Moll UM, Marchenko N, Zhang XK. p53 and Nur77/TR3-transcription factors that directly target mitochondria for cell death induction. Oncogene 2006:25:4725-43.

6. Nerenstone SR, Inde DC, Friedman MA. Clinical trials in primary hepatocellular carcinoma: current status and future directions. Cancer Treat Rev 1988;15:1-31.

7. Guan $\mathbf{X Y}$, Fang $\mathbf{Y}$, Sham JS, et al. Recurrent chromosome alterations in hepatocellular carcinoma detected by comparative genomic hybridization. Genes Chromosomes Cancer 2000:29:110-16.

8. Marchio A, Meddeb M, Pineau P, et al. Recurrent chromosomal abnormalities in hepatocellular carcinoma detected by comparative genomic hybridization. Genes Chromosomes Cancer 1997:18:59-65.

9. Wong N, Lai P, Lee SW, et al. Assessment of genetic changes in hepatocellular carcinoma by comparative genomic hybridization analysis: relationship to disease stage, tumor size, and cirrhosis. Am J Pathol 1999;154:37-43.

10. Ma NF, Hu L, Fung JM, et al. Isolation and characterization of a novel oncogene, amplified in liver cancer 1, within a commonly amplified region at 1q21 in hepatocellular carcinoma. Hepatology 2008;47:503-10.

11. Chen M, Huang JD, Hu L, et al. Transgenic CHD1L expression in mouse induces spontaneous tumors. PLoS One 2009:4:e6727.

12. Chen L, Hu L, Chan TH, et al. Chromodomain helicase/adenosine triphosphatase DNA binding protein 1-like (CHD1I) gene suppresses the nucleus-to-mitochondria translocation of nur77 to sustain hepatocellular carcinoma cell survival. Hepatology 2009;50:122-9.

13. Chen L, Chan TH, Yuan YF, et al. CHD1L promotes hepatocellular carcinoma progression and metastasis in mice and is associated with these processes in human patients. J Clin Invest 2010;120:1178-91.
14. Therasse $\mathbf{P}$, Arbuck SG, Eisenhauer EA, et al. New quidelines to evaluate the response to treatment in solid tumors. European Organization for Research and Treatment of Cancer, National Cancer Institute of the United States, National Cancer Institute of Canada. J Natl Cancer Inst 2000;92:205-16.

15. $\mathbf{~ N g ~ 1 0 , ~ S r i v a s t a v a ~ G , ~ C h u n g ~ L P , ~ e t ~ a l . ~ O v e r e x p r e s s i o n ~ a n d ~ p o i n t ~ m u t a t i o n s ~ o f ~ p 5 3 ~}$ tumor suppressor gene in hepatocellular carcinomas in Hong Kong Chinese people. Cancer 1994;74:30-7.

16. Bruix J, Boix L, Sala M, et al. Focus on hepatocellular carcinoma. Cancer Cell 2004;5:215-19.

17. Curley SA, Izzo F, Ellis LM, et al. Radiofrequency ablation of hepatocellular cancer in 110 patients with cirrhosis. Ann Surg 2000;232:381-91.

18. Hemming AW, Cattral MS, Reed Al, et al. Liver transplantation for hepatocellular carcinoma. Ann Surg 2001;233:652-9.

19. Bruix J, Sherman M. Management of hepatocellular carcinoma. Hepatology 2005:42:1208-36

20. Llovet JM, Real MI, Montana X, et al. Arterial embolisation or chemoembolisation versus symptomatic treatment in patients with unresectable hepatocellular carcinoma: a randomised controlled trial. Lancet 2002;359:1734-9.

21. Lo CM, Ngan H, Tso WK, et al. Randomized controlled trial of transarterial lipiodol chemoembolization for unresectable hepatocellular carcinoma. Hepatology 2002;35:1164-71.

22. Boucher $\mathbf{E}$, Corbinais $\mathrm{S}$, Brissot $\mathrm{P}$, et al. Treatment of hepatocellular carcinoma (HCC) with systemic chemotherapy combining epirubicin, cisplatinum and infusional 5-fluorouracil (ECF regimen). Cancer Chemother Pharmacol 2002; 50:305-8.

23. Colombo M, Sangiovanni A. The European approach to hepatocellular carcinoma. Hepatogastroenterology 2002;49:12-16.

24. Wang $\mathbf{Y}$, Wu MC, Sham JS, et al. Prognostic significance of c-myc and AIB1 amplification in hepatocellular carcinoma. A broad survey using high-throughput tissue microarray. Cancer 2002;95:2346-52.

25. Stuart K, Tessitore J, Huberman M. 5-Fluorouracil and alpha-interferon in hepatocellular carcinoma. Am J Clin Oncol 1996;19:136-9.

26. Brummelkamp TR, Bernards R, Agami R. A system for stable expression of short interfering RNAs in mammalian cells. Science 2002:296:550-3.

27. Dai $\mathbf{Y}$, Qiao L, Chan KW, et al. Adenovirus-mediated down-regulation of $\mathrm{X}$-linked inhibitor of apoptosis protein inhibits colon cancer. Mol Cancer Ther 2009:8:2762-70

28. Carette JE, Overmeer RM, Schagen FH, et al. Conditionally replicating adenoviruses expressing short hairpin RNAs silence the expression of a target gene in cancer cells. Cancer Res 2004;64:2663-7.

29. Connolly K, Mitter R, Muir M, et al. Stable XIAP knockdown clones of HCT116 colon cancer cells are more sensitive to TRAlL, taxanes and irradiation in vitro. Cancer Chemother Pharmacol 2009;64:307-16.

30. Inoue $\mathbf{H}$, Shiraki $\mathrm{K}$, Murata $\mathrm{K}$, et al. Adenoviral-mediated transfer of $\mathrm{p} 53$ gene enhances TRAIL-induced apoptosis in human hepatocellular carcinoma cells. Int $J$ Mol Med 2004;14:271-5. 
Clinical significance of CHD1L in hepatocellular carcinoma and therapeutic potentials of virus-mediated $C H D 1 L$ depletion

Leilei Chen, Yun-Fei Yuan, Yan Li, et al.

Gut 2011 60: 534-543 originally published online November 10, 2010 doi: $10.1136 /$ gut.2010.224071

Updated information and services can be found at:

http://gut.bmj.com/content/60/4/534.full.html

\section{These include:}

Data Supplement

"web only data"

http://gut.bmj.com/content/suppl/2010/11/26/gut.2010.224071.DC1.html "online appendix"

http://gut.bmj.com/content/suppl/2011/04/13/gut.2010.224071.DC2.html

References This article cites 30 articles, 7 of which can be accessed free at: http://gut.bmj.com/content/60/4/534.full.html\#ref-list-1

Email alerting Receive free email alerts when new articles cite this article. Sign up in service the box at the top right corner of the online article.

\begin{tabular}{cc}
$\begin{array}{c}\text { Topic } \\
\text { Collections }\end{array}$ & $\begin{array}{c}\text { Articles on similar topics can be found in the following collections } \\
\text { Hepatic cancer (326 articles) }\end{array}$ \\
\hline
\end{tabular}

Notes

To request permissions go to:

http://group.bmj.com/group/rights-licensing/permissions

To order reprints go to:

http://journals.bmj.com/cgi/reprintform

To subscribe to BMJ go to:

http://group.bmj.com/subscribe/ 